Review Article

\title{
Dealing with iron metabolism in rice: from breeding for stress tolerance to biofortification
}

\author{
Railson Schreinert dos Santos ${ }^{1,2}$, Artur Teixeira de Araujo Júnior ${ }^{2}$, Camila Pegoraro ${ }^{1}$ and Antonio Costa de \\ Oliveira $^{1,2}$ \\ ${ }^{1}$ Plant Genomics and Breeding Center (CGF), Universidade Federal de Pelotas, Pelotas, RS, Brazil. \\ ${ }^{2}$ Technology Development Center (CDTec), Universidade Federal de Pelotas, Pelotas, RS, Brazil.
}

\begin{abstract}
Iron is a well-known metal. Used by humankind since ancient times in many different ways, this element is present in all living organisms, where, unfortunately, it represents a two-way problem. Being an essential block in the composition of different proteins and metabolic pathways, iron is a vital component for animals and plants. That is why iron deficiency has a severe impact on the lives of different organisms, including humans, becoming a major concern, especially in developing countries where access to adequate nutrition is still difficult. On the other hand, this metal is also capable of causing damage when present in excess, becoming toxic to cells and affecting the whole organism. Because of its importance, iron absorption, transport and storage mechanisms have been extensively investigated in order to design alternatives that may solve this problem. As the understanding of the strategies that plants use to control iron homeostasis is an important step in the generation of improved plants that meet both human agricultural and nutritional needs, here we discuss some of the most important points about this topic.
\end{abstract}

Keywords: iron toxicity, mineral malnutrition, Fe-enrichment, Quantitative Trait Loci.

Received: February 18, 2016; Accepted: September 22, 2016.

\section{Introduction}

Iron is the fourth most abundant element in the earth's crust, where ferric iron $\left(\mathrm{Fe}^{3+}\right)$ and ferrous iron $\left(\mathrm{Fe}^{2+}\right)$ are the most common forms (Hori et al., 2015). While $\mathrm{Fe}^{3+}$ is insoluble and its uptake is difficult, $\mathrm{Fe}^{2+}$ is soluble and readily available to plants. When the soil is aerated and in alkaline $\mathrm{pH}, \mathrm{Fe}$ is oxidized as insoluble iron oxides, but in flooded soils, which are in anaerobic conditions, $\mathrm{pH}$ decreases and there is a reduction of $\mathrm{Fe}^{3+}$ to $\mathrm{Fe}^{2+}$ (Morrissey and Guerinot, 2009). This event is responsible for the low availability of $\mathrm{Fe}$ in upland soils and for its high availability in flooded soils.

$\mathrm{Fe}$ is an essential micronutrient for both animals and plants. In mammals iron is part of the structure of a diversity of proteins (hemoglobin, myoglobin, cytochromes, flavoproteins, heme-flavoproteins, transferrin, lactoferrin, ferritin, hemosiderin, sulfur, non-heme enzymes) (Institute of Medicine, 2001). In plants, Fe serves as a component of many vital enzymes such as cytochromes of the electron transport chain, acting in photosynthesis and in the electron transfer (through Fe-S clusters), in respiration, and other important metabolic pathways (Briat and Lobreaux, 1997;

Send correspondence Antonio Costa de Oliveira. Plant Genomics and Breeding Center, Universidade Federal de Pelotas; PO Box 354, Campus Universitário, S/N, 96160-000, Capão do Leão, RS, Brazil. E-mail: acostol@cgfufpel.org
Kobayashi and Nishizawa, 2012; Rout and Sahoo, 2015). It also participates in the Fenton reaction catalyzing the generation of hydroxyl radicals $(\mathrm{OH})$, and reactive oxygen species (ROS) that can cause irreversible damage to the cell (Wu et al., 2014). Thus, Fe stress can be caused either by deficiency as well as by excess (Connolly and Guerinot, 2002).

Iron deficiency can cause alterations in root morphology (Morrissey and Guerinot, 2009; Giehl et al., 2012; Gruber et al., 2013) and chlorosis of young leaves, therefore reducing yield (Kobayashi and Nishizawa, 2014). To prevent the shortage of this element, plants have developed two different absorption strategies: strategy I, which is used by higher plants, except for members of the Poaceae family. In this strategy the enzyme $\mathrm{H}^{+}$ATPase (AHA) mediates the release of hydrons from the roots to the rhizosphere, increasing the solubility of $\mathrm{Fe}^{3+}$, and the Phenolics Efflux Zero 1 (PEZ1) transports phenolics, such as protocatechuic acid, making it possible to take up and use apoplastic precipitated Fe (Ishimaru et al., 2011; Rodríguez-Celma and Schmidt, 2013). A comparison between two model species, Arabidopsis and Medicago truncatula, showed further evidence that the production and secretion of phenolic compounds is critical for the uptake of iron from sources with low bioavailability, but dispensable under conditions where iron is readily available (Rodríguez-Celma et al., 2013; Rodríguez-Celma and Schmidt, 2013). 
Also, in strategy I, Ferric Reductase Oxidase (FRO2) mediates the $\mathrm{Fe}^{3+}$ reduction to $\mathrm{Fe}^{2+}$, and Iron Regulated Transporter1 (IRT1) is responsible for $\mathrm{Fe}^{2+}$ absorption by the roots (Connolly and Guerinot, 2002; Kobayashi and Nishizawa, 2012).

Strategy II, which is specific of grasses, is based on biosynthesis and secretion of compounds called phytosiderophores (PS), which are results of the action of nicotianamine synthase (NAS), nicotianamine aminotransferase (NAAT) and deoxymugineic acid synthase (DMAS) (Shojima et al., 1990). TOM1/OsZIFL4, which belongs to the major facilitator superfamily (MFS) (Pao et al., 1998), is involved in siderophore export necessary in $\mathrm{Fe}$ acquisition (Furrer et al., 2002). These PSs can bind to $\mathrm{Fe}^{3+}$ forming the soluble complex Fe(III)-PS, and these complexes in the rhizosphere can be taken up into root cells through the action of YELLOW STRIPE-LIKE PROTEINS (YSLs) (Inoue et al., 2009; Lee et al., 2009a; Nozoye et al., 2011). In rice there are 18 YS1-like (OsYSL) genes, and OsYSL15 transports $\mathrm{Fe}(\mathrm{II})$-PS and it is likely more relevant for Fe(III)-PS (Romheld and Marschner, 1986; Curie et al., 2001; Inoue et al., 2009; Lee et al., 2009a). Rice (Oryza sativa $\mathrm{L}$.) uses strategy II, but is also able to absorb $\mathrm{Fe}^{2+}$ directly from the rhizosphere through IRT1 (Zaharieva and Römheld, 2000; Bughio et al., 2002; Ishimaru et al., 2006; Kobayashi and Nishizawa, 2014).

The high level of $\mathrm{Fe}^{2+}$ found in some flooded soils can be toxic to plants (Mongon et al., 2014). The toxicity caused by excessive Fe can occur directly and indirectly. The direct toxicity occurs when there is too much absorption and excessive accumulation of this element in tissues followed by the appearance of brown-dark spots in the leaves (leaf-bronzing) (Becker and Asch, 2005; Morrissey and Guerinot, 2009). The indirect damage is caused by the prevention of the uptake, transport and utilization of other nutrients (e.g.: P, K, Ca, Mg, Mn, and $\mathrm{Zn}$ ) due to the iron plaque that forms when $\mathrm{Fe}^{3+}$ is deposited in the apoplast of rice roots (Sahrawat, 2004; Zhang et al., 2014). Both situations affect plant growth, development and productivity, leading to significant yield losses. To adapt to this condition, rice plants have developed different mechanisms of tolerance (Type I, Type II and Type III) that are based on specific forms of use, exclusion and storage of iron. In Type I there is an oxidation and precipitation of $\mathrm{Fe}^{2+}$ on the root surface, while in Type II the storage occurs in a less reactive form, in ferritin protein. Type III mechanism is based on tolerance to the ROS formed in Fenton's reaction (Wu et $a l ., 2014)$. Another thing that can occur is the annulment of the absorbed $\mathrm{Fe}^{2+}$ by its storage in old or less active leaves or exclusion via symplast (Becker and Asch, 2005).

Physiological disorders caused by Fe excess are common in cultivated rice in the regions of Africa, Asia and South America (Shahid et al., 2014). However, despite the high amount of Fe in the soil, which can even be toxic to the plant, little is accumulated in rice grains. In addition, the accumulation of iron in the grain occurs in the outermost lay- ers being lost during the industrial processing (Doesthale et al., 1979; Sperotto et al., 2012). Thus, rice contributes very little to meet the need of Fe intake in the human diet, not being an effective way of preventing anemia.

More than two billion people worldwide suffer from anemia, and more than $50 \%$ of these cases are caused by $\mathrm{Fe}$ deficiency (Arcanjo et al., 2013). The Fe-deficiency anemia (IDA) affects more dramatically the continents of Africa and Asia, where IDA is a major public health problem, prevalent in young women and children (Moretti et al., 2006; Visser and Herselman, 2013), since it is responsible for the death of almost one million individuals per year (Aung et al., 2013).

Biofortification is an interesting strategy to solve the problem of IDA, especially for people who cannot change their eating habits due to financial, cultural or religious issues. In this sense, not only increasing the amount of iron in grains, but also decreasing the content of inhibitors of Fe absorption commonly found in plants can improve the diets (Lucca et al., 2001; Raboy, 2002; Schuler and Bauer, 2012). In addition, biofortification is a sustainable strategy. In this sense rice can be the ideal species for biofortification since it is a staple food that is especially important for developing countries, where IDA is even more severe. Also, rice is grown in flooded soils, where Fe availability is higher (Becker and Asch, 2005), and has its mechanisms of absorption, translocation and homeostasis Fe better understood than most of the species (Masuda et al., 2012).

Global rice production is 741 million tons at approximately 165 million hectares. Rice is not only the second most cultivated cereal in the world, with important social and economic function, but is also an ideal model for functional genomics studies in monocots (FAOSTAT, 2015; Yao et al., 2015). The availability of different rice genomes of different subspecies has enabled the study of many genes and metabolic pathways (Goff et al., 2002; IRGSP - International Rice Genome Sequencing Project, 2005).

Considering the importance of rice in nutrition and economy as well as the impact of iron deficiency and excess in the life of plants and animals, in this review we will discuss the highlights of the uptake pathways, translocation, homeostasis and $\mathrm{Fe}$ accumulation in the grain. Understanding these points is essential both to solve the problem of sensitivity to high levels of Fe as to allow Fe-biofortification.

\section{Identifying regulatory pathways}

According to the availability of $\mathrm{Fe}$ in the soil, plants have developed mechanisms to control and regulate the absorption, translocation and subcellular storage of this mineral. Classical studies associated with the emergence of modern and advanced tools of genomics, transcriptomics and proteomics have enabled in-depth understanding of homeostasis of Fe in plants (Kobayashi and Nishizawa, 2012). The uptake of Fe occurs by using strategy I or reduc- 
tion (non Poaceae), strategy II or chelation (Poaceae), and a combination of strategies I and II (rice) (Figure 1) (Ishimaru et al., 2006; Zhang et al., 2012; Yang et al., 2013; Ricachenevsky and Sperotto, 2014; Finatto et al., 2015). The key genes involved in strategy I are AHA2 (protonation of the rhizosphere), FRO2 (reduction of $\mathrm{Fe}^{3+}$ to $\mathrm{Fe}^{2+}$ ), and IRT1 ( $\mathrm{Fe}^{2+}$ transport into the root) (Kim and Guerinot, 2007; Hindt and Guerinot, 2012).

In Arabidopsis thaliana (L.) Heynh there are eight homologues of FRO (AtFRO1 to AtFRO8), while in $O$. sativa there are only two (OsFRO1 and OsFRO2) (Victoria et al., 2012). The gene IRT presents 15 homologues in $A$. thaliana, (AtIRT1, AtIRT2, AtIRT3, AtZIP1 to AtZIP12) and 11 in O. sativa (OsIRT1, OsIRT2, OsZIP1 to OsZIP10) (Ishimaru 2005; Ishimaru et al., 2006; Kim and Guerinot 2007). A. thaliana presents 12 homologues of the gene AHA (AtAHA1 to AtAHA12) (Santi and Schmidt, 2009) and O. sativa ten (OsA1 to OsA10) (Zhu et al., 2009; Li et al., 2015). Not all members of FRO, ZIP and AHA families are directly involved with Fe capture (Michelet and Boutry, 1995; Bernal et al., 2012; Milner et al., 2013).

In conditions of Fe deficiency there is an induction of IRT1, FRO2 and several AHAs (Colangelo and Guerinot, 2004; Santi and Schmidt, 2009; Hindt and Guerinot, 2012). Studies conducted in $A$. thaliana demonstrate that the low availability of Fe leads to the induction of transcription factor (TF) FER-like iron deficiency-induced transcription factor (FIT) which regulates AtFRO2 at the level of mRNA accumulation and AtIRT1 at the level of both mRNA and protein accumulation (Eide et al., 1996; Vert et al., 2002; Colangelo and Guerinot, 2004). The co-expression of FIT with other TFs of the Basic helix-loop-helix (AtbHLH38/39) family directly regulates the expression of IRT1 and FRO2, increasing iron accumulation (Yuan et al., 2008; Hindt and Guerinot, 2012). There are no orthologs of FIT in rice, but $A t b H L H 38 / 39$ are similar to OsIRO2 (Hindt and Guerinot 2012) that regulates genes related to transport of $\mathrm{Fe}(\mathrm{III})-\mathrm{PS}$, but does not regulate OsIRT1 (Ogo et al., 2007).

The FIT gene is regulated by signaling molecules such as auxin and ethylene, synthesized in conditions of iron deficiency. In Arabidopsis the lack of Fe induces an increase in auxin synthesis, resulting in increased expression of the genes FIT and FRO2 (Chen et al., 2010). Similarly to what happens to auxin, an increase in ethylene synthesis is also noticed under these conditions, an event that cause the upregulation of FIT (Lucena et al., 2006) and therefore of FRO and IRT. FIT interacts with the TFs Ethylene insensitive 3 (AtEIN3) and Ethylene insensitive 3-like1 (AtEIL1) emphasizing the importance of ethylene signaling in response to Fe deficiency (Lingam et al., 2011). It is interesting to note that there is a plethora of bHLH genes involved in iron uptake regulation and extensive additional information is available (Bashir et al., 2010; Zheng et al., 2010; Zhao et al., 2014; Li et al., 2016).
Just as auxin and ethylene, nitric oxide (NO) has its synthesis increased in conditions of Fe deficiency. NO acts as a positive regulator of genes whose products act on $\mathrm{Fe}$ uptake (Hindt and Guerinot, 2012). Conversely, under conditions of $\mathrm{Fe}$ excess, three ZIP genes and OsFRO2 are induced in rice (Finatto et al., 2015).

In Arabidopsis the Popeye (AtPYE) and Brutus (AtBTS) genes are, respectively, a TF and an E3 ubiquitin ligase that also participate in the regulation of Fe absorption. These proteins act in sensitizing the root response to the availability of Fe, regulating Fe homeostasis (Long et al., 2010). In rice, the genes OsIRO3 (Zheng et al., 2010) and OsHRZ1/OsHRZ2 (Kobayashi et al., 2013), have been identified. IRO3 is an ortholog of AtPYE, and HZRI and $H Z R 2$ are orthologs of AtBTS.

Strategy II (Figure 1) includes the participation of genes that act in the cycle of PSs precursors - METHIONINE and S-ADENOSYL-L-METHIONINE (5'-methylthioadenosine nucleosidase - MTN, Methylthioribose kinase - MTK, Methylthioribose-1-phosphate isomerase IDI2 and dehydrase enolase phosphatase - DEP, s-adenosyl-1-methionine synthetase-SAMS) (Kobayashi et al., 2005; Suzuki et al., 2006), in the synthesis of PSs (NAS, $N A A T, D M A S$, Dioxygenases - IDS2/IDS3) (Nakanishi et al., 2000; Kobayashi and Nishizawa, 2012), binding of PSs to $\mathrm{Fe}(\mathrm{III})$ (Nozoye et al., 2011), and in the transport of the complex Fe(III)-PSs into the root (YS1 and YSL) (Curie et al., 2001; Inoue et al., 2009; Lee et al., 2009a; Kobayashi and Nishizawa, 2012). Four homologues of the gene $N A S$ are present in arabidopsis (AtNAS1, AtNAS2, AtNAS3 and AtNAS4) and three in rice (OsNAS1, OsNAS2 and OsNAS3) (Victoria et al., 2012). Six homologues of the NAAT gene (OSNAAT1 to OsNAAT6), and only one DMAS gene (OSDMAS1) are present in rice (Bashir et al., 2006; Widodo et al., 2010). For gene $Y S L$, eight homologues were identified in Arabidopsis (AtYSL1 to AtYSL8) and 18 in rice (Os YSL1 to YSL18) (Victoria et al., 2012).

Like as the genes involved in strategy I, genes associated with strategy II are induced in iron deficiency (Ricachenevsky and Sperotto, 2014). The TFs Iron deficiency responsive element binding factor 1 (IDEF1 and IDEF2) and Iron regulated basic helix-loop-helix (IRO2) have been identified as regulators of key genes that control Fe uptake, including the synthesis of PSs in rice (Itai et al., 2013). Under Fe deficiency the OsIDEF1 upregulates genes whose products act in capture and use of Fe in rice, such as OsIRO2, OsYSL15, OsYSL2, OsIRT1, OsNAS1, OsNAS2 and OsNAS3 (Kobayashi et al., 2009). The TF IDEF 1 binds to Iron Deficiency-responsive Element 1 (IDE1), while IDEF2 binds to IDE2, both present in the promoter region of genes associated with Fe deficiency (Kobayashi et al., 2007; Ogo et al., 2008). Moreover, OsIRO3 is induced in Fe deficiency and acts as a negative regulator of genes related to this condition in rice (OSNAS1, OsNAS2, OsIRO2, OsIRT1, OsYSL15 and OsNRAMP1) (Zheng et al., 2010). 


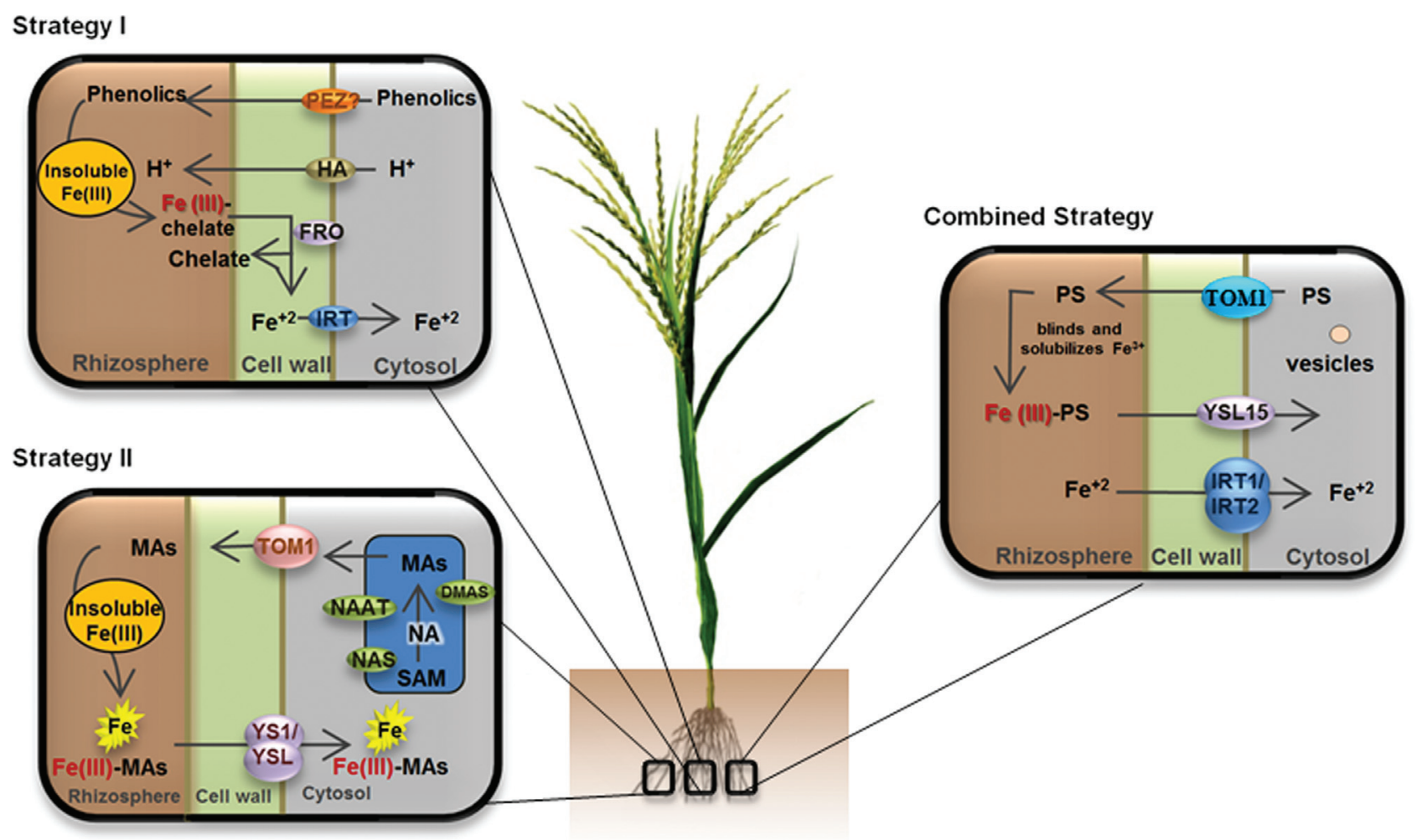

Figure 1 - Absorption and translocation of iron in rice. Adapted from Palmer and Guerinot (2009); Kobayashi and Nishizawa (2012); Bashir et al. (2013a).

In conditions of Fe toxicity the genes OsNAS1, OsNAS2, OSYSL15, OSYSL16 and OSNRAMP1 were repressed in rice roots (Quinet et al., 2012). In a similar study, Finatto et al. (2015) reported the induction of the genes OSNAAT1, OSYSL1 and OSYSL17 in rice plants grown under excessive Fe.

After Fe capture by the roots, this is transported to other organs, a process that involves several steps, passing through symplast, xylem (transpiration stream) and phloem (Kim and Guerinot, 2007). When Fe enters the symplast it is oxidized and ligated to chelating molecules (Miroslav, 1998). Chelators that can bind to Fe are, as shown in Figure 2, citrate, nicotianamine (NA) and mugineic acid (MA) (Kobayashi and Nishizawa, 2012).

It has been proposed that NA facilitates Fe movement in and out of the phloem (through YSLs), while the movement of Fe within the phloem occurs via Iron Transport Proteins (ITP), dehydrins (DHN) that bind $\mathrm{Fe}^{3+}$ but not $\mathrm{Fe}^{2+}$ (Krüger et al., 2002; Hell and Stephan, 2003; Morrissey and Guerinot, 2009). In A. thaliana the Ferric Reductase Defective 3 (AtFDR3) encodes a transmembrane protein belonging to the family of Multidrug and toxin efflux transporters (MATE) that facilitates the transport of citrate in the xylem (Durrett et al., 2007).

In rice, a citrate transporter called OSFRDL1 is required for efficient translocation of Fe-citrate complex (Yokosho et al., 2009). In rice plants under conditions of Fe excess, the induction of three genes belonging to the MATE family, which may be involved in reducing ROS production in mitochondria, was observed (Finatto et al., 2015). Genes belonging to YSL and IRT families, as well are not only involved in iron uptake, but also in the transport of this element through the plant. Different YSL genes transport different complexes. In rice for example, OSYSL2 transports Fe(II)NA (Koike et al., 2004) while OsYSL15 product

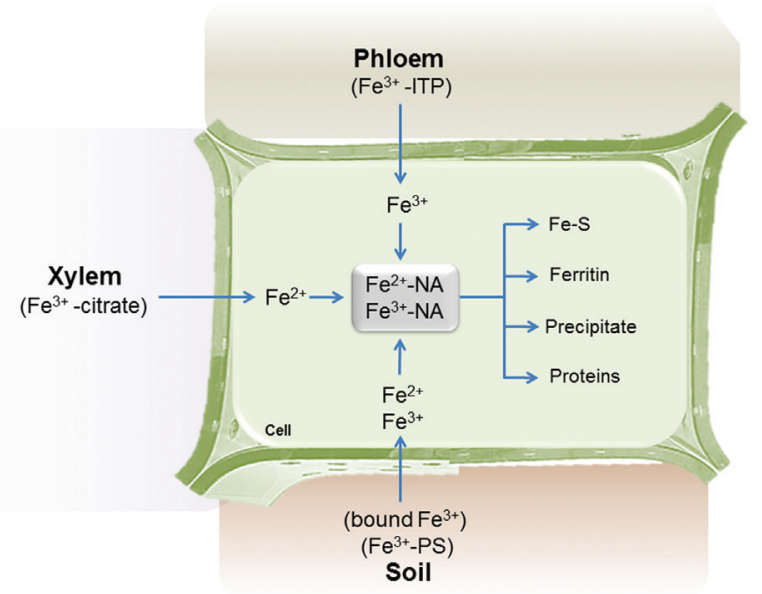

Figure 2 - Role of nicotianamine (NA) in iron metabolism in plant cells. Iron can enter the plant cell through various strategies depending on the nature of the iron source. In this context NA is an important chelator that is able to provide iron in a functional form, avoiding precipitation and catalysis. Adapted from Hell and Stephan (2003). 
transports Fe(III)-DMA (Lee et al., 2009a). OsIRT1 is expressed not only in roots, but also in rice leaves and stems, indicating its participation in the Fe transport over long distances (Narayanan et al., 2007).

To be assimilated by the leaves, $\mathrm{Fe}^{3+}$ is reduced by FRO enzymes. FRO7 of $A$. thaliana plays a role in chloroplast iron acquisition and is required for efficient photosynthesis in young seedlings and is especially important when plants are under iron-limiting conditions (Jeong et al., 2008). The LeFRO1 of Lycopersicum esculentum Mill. (Li et al., 2004), PsFRO1 of Pisum sativum (Waters et al., 2002) and AtFRO6 in A. thaliana are expressed in the aerial part (Feng et al., 2006), indicating their participation in reduction of $\mathrm{Fe}^{3+}$. A great diversity of these proteins has been studied, and these are not only involved in iron, but also in copper homeostasis. The diverse roles of the FRO family have recently been reviewed (Jain et al., 2014).

After reduction, $\mathrm{Fe}$ is transported to other organs of the plant. This transport is performed via the phloem nicotianamine chelator (NA) (Takahashi et al., 2003), which is synthesized by the enzyme Nicotianamine synthase (NAS). The Fe transport also occurs through family members of the NATURAL RESISTANCE-ASSOCIATED MACROPHAGE PROTEIN (NRAMP) (Nevo and Nelson, 2006). NRAMP carriers are related to the subcellular transport of $\mathrm{Fe}$ and its partitioning in vacuoles and/or plastids (Curie et al., 2000). Six NRAMP genes were found in Arabidopsis and eight in rice (OsNRAMP1-OsNRAMP8) (Victoria et al., 2012).

In rice, OsNRAMP1 is expressed mainly in roots, OsNRAMP2 in leaves, and OsNRAMP3 is expressed in both tissues (Belouchi et al., 1997). In conditions of Fe excess, Quinet et al. (2012) noticed the repression of the gene OsNRAMP1, which is also involved in cadmium $(\mathrm{Cd})$ accumulation (Takahashi et al., 2011a,b), while Finatto et al. (2015) observed the induction of another NRAMP gene, OsNRAMP6. OsNRAMP5 is important not only for Fe, but also for manganese (Mn) and Cd transport (Ishimaru et al., 2012; Sasaki et al., 2012). OsNRAMP3 is a vascular bundles-specific Mn transporter, showing once more that Mn commonly shares the same transporters with Fe in plants (Pittman, 2005; Cailliatte et al., 2010; Yang et al., 2013).

Inside the cell, Fe can be incorporated into proteins, stored in plastids and mitochondria, where it is found associated with ferritin (Duy et al., 2011; Vigani et al., 2013), or even in the vacuole of the cell (Gollhofer et al., 2014) (Figure 1). This compartmentalization can be useful for Fe homeostasis, especially in conditions of excess of this element. Ferritin is an iron storage protein that avoids damage caused by free radicals produced by the interaction iron/dioxygen (Goto et al., 1999). This protein has the capacity to store more than $4,500 \mathrm{Fe}$ atoms in a soluble, non-toxic and bioavailable form (Briat and Lobreaux, 1997). In Oryza glaberrima S. and O. sativa the tolerance to Fe toxicity seems to be associated with ferritin synthesis (Majerus et al., 2007; Silveira et al., 2009). A. thaliana has four homologues of ferritin encoding genes (AtFER1 to AtFER4), while in O. sativa two of these can be found (OSFER1 and OsFER2) (Silveira et al., 2009). The Fe-dependent regulation of AtFER1 and ZmFER1 genes depends on the presence of a cis-element called Iron-dependent Regulatory Sequence (IDRS) in their promoter regions. The IDRS element is involved in the repression of FER genes in plants that grow under low concentrations of Fe (Petit et al., 2001). In case of Fe excess, the genes OsFER1 and OsFER2 show increased amounts of transcripts, with OsFER2 being preferably upregulated (Stein et al., 2009). Similar results were found by Quinet et al. (2012), who also observed the induction of OSFER1 and OSFER2 genes in stress caused by excess of $\mathrm{Fe}$ in the soil. In other species, induction of FER genes by toxic amounts of Fe has also been observed.

Vacuoles are multifunctional organelles dynamically adjusted according to environmental conditions. This organelle has buffering capacity serving as a reservoir of metabolites, minerals, nutrients, and also as a deposit for toxic compounds, being crucial for the process of detoxification and for cellular homeostasis (Marty, 1999; Peng and Gong, 2014). The uptake of Fe by the vacuole is mediated by FERROPORTIN (FPN) (Morrissey et al., 2009) and by members of a family of VACUOLAR IRON TRANSPORTERS (VIT) (Zhang et al., 2012). In A. thaliana three homologues of FPN (AtFPN1/AtIREG1, AtFPN2/AtIREG2 and AtFPN3/AtIREG3) were found (Curie and Briat, 2003; Morrissey and Guerinot, 2009; Merlot et al., 2014), while in $O$. sativa only two of these genes (OsFPN1/OsFerroportin; OsFPN2/IREG3) were detected (Bashir et al., 2011; Merlot et al., 2014). In Arabidopsis, iron accumulation in the vacuole of seed cells depends on AtVIT1. This protein is localized in the vacuolar membrane, and the gene is expressed in the developing embryo, seed and, in young seedlings, where the protein is predominantly associated with the vasculature (Kim et al., 2006). In rice the vacuolar membrane transporters encoded by OsVIT1 and OsVIT2 genes are involved in storage of iron in vacuoles of flag leaves, and the inhibition of these results in an increase of Fe in the seed, suggesting that new mechanisms are activated under this condition (Zhang et al., 2012), and under conditions of Fe excess, OsVIT1 was increased (Finatto et al., 2015). In Arabidopsis, Fe remobilization from the vacuole to the cytoplasm is mediated by NRAMP3 and NRAMP4 (Peng and Gong, 2014).

\section{Quantitative Trait Loci}

In anaerobic conditions, high amounts of $\mathrm{Fe}^{2+}$ are taken up by plants, resulting in the accumulation of this element in the cell (Santos and de Oliveira, 2007). In rice, there is a differential response among cultivars to stress by Fe excess. When both susceptible and tolerant cultivars, BR-IRGA 409 and EPAGRI 108 respectively, were subjected to high concentrations of Fe there was less accumu- 
lation of this element and greater accumulation of ferritin in the tolerant cultivar, suggesting that this protein may be involved in this mechanism of tolerance (Silveira et al., 2009). However, a study by Panda et al. (2014) found that when there is Fe accumulation, the activity of aconitase and ferritin levels are higher in a cultivar that accumulates higher concentrations of Fe compared to the cultivar that has a lower concentration of this element. It is also interesting to highlight that a previous study showed that the accumulation of iron is not parallel to the level of ferritin expression in rice seeds overexpressing the SoyFER gene (of soybean ferritin), suggesting that Fe accumulation may be limited by the uptake and transport of this element (Qu et al., 2005). According to these studies, the mechanisms associated with tolerance to toxicity and accumulation of Fe are not well understood. However, studies related to the identification of Quantitative Trait Loci (QTLs) and genes whose products are responsible for the homeostasis of Fe and the accumulation of this mineral in the grain have been conducted (Figure 3 and Table S1), and the results of these surveys can assist breeding programs for toxicity tolerance, as well as biofortification for Fe content (Wu et al., 1998; Wan et al., 2003; Dufey et al., 2009; Shimizu, 2009; Wu et $a l ., 2014)$. In this regard, three loci were identified on rice chromosomes 7, 8 and 9 that explain around $19-30 \%$ of the difference in the concentration of Fe in grains (Gregorio et al., 2000). Another study that did not analyze QTLs but gene expression, showed that higher concentrations of Fe in grains were positively correlated with the expression of the genes OsYSL14, OSNAC5, and negatively correlated with OsNRAMP7, OsNRAMP8 and OsFRO1 expression (Sperotto et al., 2010). On the other hand, OsFER1, OsNRAMP4, OsNRAMP5, OsNRAMP6, OsYSL6, Os YSL12, Os YSL4, OsZIP8, OsZIP10 were correlated with higher concentration of Fe in grains. The functional characterization of these genes can help in getting biofortified rice genotypes with higher concentrations of $\mathrm{Fe}$ in grains. In a QTL analysis for tolerance to bronzing, using an F3 popula- tion from the cross between cv. Gimbozu (japonica genotype which is tolerant to Fe excess) and cv. Kasalath (indica genotype which is susceptible to Fe excess), seven QTLs associated with this feature were detected. These QTLs, which are located on chromosomes 1, 2, 7, 8 and 12, explain $99 \%$ of the phenotypic variation for bronzing and showed no detectable epistatic effect (Shimizu, 2009). In a population generated from the cross between cv. Azucena (tolerant japonica) and cv. IR64 (susceptible indica), a QTL on chromosome 1 was found associated with leaf bronzing index (Dufey et al., 2009). The association of this region with the bronzing index had already been detected earlier (Wan et al., 2003; Wu et al., 1998). Also in a QTL analysis in a population obtained from the cross between cv. Kasalath (susceptible indica) and cv. Koshihikari (tolerant japonica), a QTL on chromosome 3 was found associated with $\mathrm{Fe}$ concentration in the shoot (Fukuda et al., 2012). In a study conducted by Wu et al. (2014), populations from the crosses IR29 (susceptible indica) x Pokkali (tolerant indica) and Nipponbare (moderately tolerant $j a$ ponica) x Kasalath (highly susceptible japonica) were used for identification of QTLs associated with tolerance to Fe excess. In the population IR29/Pokkali the authors identified seven QTLs for leaf bronzing, located on chromosomes 1, 2, 4, 7 and 12, explaining 9.2 to $18.7 \%$ of the phenotypic variation. In a Nipponbare/Kasalath/Nipponbare backcross inbred population, three QTLs were mapped on chromosomes 1, 3 and 8, and these QTLs explain 11.6 to $18.6 \%$ of the phenotypic variation. Additional studies demonstrated that the QTL on chromosome 1 was associated with shoot tolerance, and the QTL on chromosome 3 was associated with exclusion of Fe in roots. Similarly to the QTL studies for stress tolerance to Fe, much effort has been made in identifying QTLs associated with $\mathrm{Fe}$ content in grains. Four QTLs for Fe accumulation ( $q \mathrm{Fel}, q \mathrm{Fe} 3, q \mathrm{Fe} 4$ and $q \mathrm{Fe}$ ) located on chromosomes 1, 3, 4 and 7 , accounting, respectively, for $16.2 \%, 21.4 \%, 9.7 \%$ and $15.5 \%$ of the phenotypic variation, were found in an F6

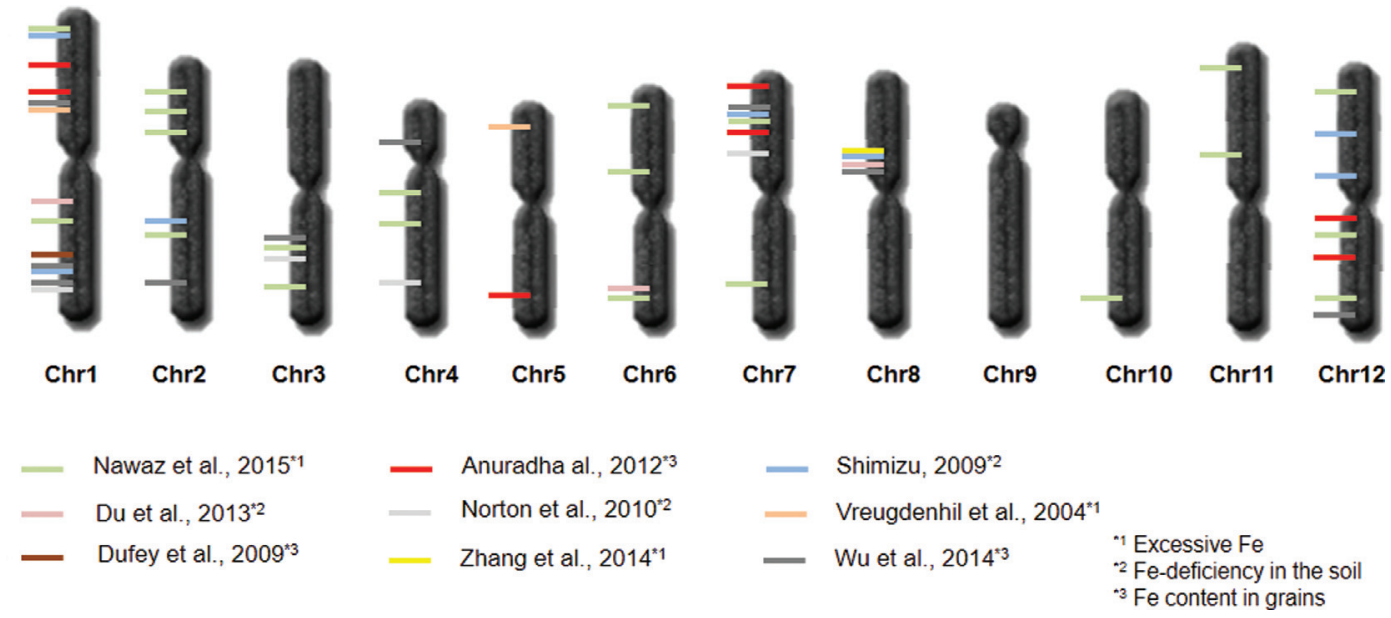

Figure 3 - QTLs related to Fe metabolism. Map with the location of different QTLs related to tolerance to low and/or excessive amounts of Fe in the soil, and/or related to the variation of Fe content in grains. 
population from the cross cv. Bala (indica) x Azucena (japonica) (Norton et al., 2010). Using Composite Interval Mapping on an F6 population from the cross Madhukar x Swarna, it was possible to identify seven QTLs associated with iron accumulation $(q \mathrm{Fe} 1.1, q \mathrm{Fe}$ 1.2, qFe5.1, qFe7.1, $q \mathrm{Fe} 7.2, q \mathrm{Fe} 12.1 \mathrm{e} q \mathrm{Fe} 12.2)$, which are located on chromosomes 1, 5, 7 and 12 (Anuradha et al., 2012). The candidate genes in these QTLs are: OsYSL1 (LOC_Os01g13710), which is located within qFe1.2; OsMTP1 (LOC_Os05g03780) located within qFe5.1; OsNas 3 (LOC_Os07g48980) located within $q F e 7.1$ and $q F e 7.2$; OsNRAMP1 (LOC_Os07g15460) located within qFe7.2; and OsZIP8 (LOC Os07g12890) located $0.3 \mathrm{Mb}$ right of $q \mathrm{Fe}$ 12.1. Most phenotypic variance was explained by the QTL on chromosome 12 (71\%) (Anuradha et al., 2012).

Mapping of a population derived from the cross Chunjiang 06 (japonica) x TN1 (indica) detected three QTLs for Fe accumulation in grains. The QTLs are located on chromosomes 1, 6 and 8, explaining, respectively 15.7 , 10.6 and $22.3 \%$ of the phenotypic variation for Fe accumulation in grains (Du et al., 2013). A QTL related to Fe concentration, was detected on chromosome 8 through the study of a population from the cross cv. Lemont (japonica) $\mathrm{x}$ cv. TeQing (indica) (Zhang et al., 2014). A collection of Dale Bumpers National Rice Research Center of the USDA ARS, Stuttgart, AR, USA composed by 221 accesses of $O$. sativa, five accesses of $O$. glaberrima, two accesses of Oryza rufipogon Griff. and one of Oryza nivara Sharma et Shastry has been mapped aiming the identification of QTLs for different contents of minerals in the grain (Nawaz et al., 2015). In this study, the authors identified 11 genetic regions responsible for binding and transport of $\mathrm{Fe}$, comprising the genes OsZIP1 (Os01g0972200), OsHMA4 (Os02g0196600), OsACA2 (Os02g0176700), OsZIP2 (Os03g0411800), OsCNGC (Os03g0758300), OsZIP3 (Os04g0613000), OsZIP5 (Os05g0472700), OsZIP9 (Os05g0472400), OsHma2 (Os06g0700700), Abc transporter (Os06g0607700), OsNAS3 (Os07g0677300), Heavy metal transporter (Os07g0671400), Chy zinc finger (Os10g0456800) and OsACA9 (Os12g0136900). In A. thaliana, two QTLs were identified on chromosomes 1 and 5 , in a region in which genes (ZIP10 and NAS1) are associated with $\mathrm{Fe}$, playing a role in cation translocation (Vreugdenhil et al., 2004). Although further studies are required for the elucidation of mechanisms and genes related with the increase of iron concentration in seeds and stress tolerance for Fe excess, much work has already been developed in QTL mapping and its association with other metabolic pathways (Wan et al., 2003; Shimizu, 2009).

\section{Phylogeny}

A phylogenetic study on members of gene families related to Fe homeostasis (NAS, NRAMP, YSL, FRO and IRT) was conducted in $O$. sativa, $A$. thaliana, Physcomitrella patens (Hedw.) Bruch \& Schimp. and other monocots and dicots (Victoria et al., 2012). In this study, the authors found that $F R O$ genes can be grouped into two clusters, but these do not separate monocots, dicots and bryophytes, a first clue indicating that the divergence of these genes occurred even before the diversification of land plants. Conversely, for NAS genes the formation of a group with monocots and dicots was observed. In the IRT family the genes were grouped into different clusters that separate monocots, dicots and bryophytes. For NRAMP genes, no evidence for divergence between groups of plants was observed, since genes from monocots and dicots were together in different clusters. Finally, the authors found that YSL genes possibly went through two duplication events, which probably occurred before the divergence of monocots and dicots (Victoria et al., 2012).

Phylogenetic analyses were also performed by Gross et al. (2003). In this study they analyzed a total of 43 genes belonging to five families: YS, FRO, ZIP, NRAMP, and ferritin proteins. The analysis of the $Y S$ family showed a relationship between predicted members of rice, Arabidopsis and maize (Zea mays L.), indicating that the putative new genes were homologous to maize $Y S$, indicating that these may also have a role in Fe transport. The proteins from family FRO were separated from the burst oxidases, with a subdivision of FRO sequences, having $O S F R O 1$ in one group and $O s F R O 2$ in another. Members of the ZIP family were grouped in a single tree, with $O s Z I P 1$ and $O s Z I P 6$ more distantly related. The NRAMP family was divided into two classes, one more similar to AtNRAMP1 and another to AtNRAMP2, in which the number of exons is determinative in grouping these sequences. The ferritin family showed a separation between each of the species analyzed, where mammalian ferritins were separated from their respective homologues. The separation was also noticed between monocots and dicots, and first we can observe the divergence of Arabidopsis genes, before genes from maize and rice diverge from each other.

\section{Strategies for Fe biofortification in rice}

Biofortification is a process that increases the bioavailability of essential elements in the edible part of plants (White and Broadley, 2005; Zielinska-Dawidziak, 2015). Although $\mathrm{Fe}$ is the fourth most abundant element in the earth's crust, little of this element is available for human nutrition by grains (Kim and Guerinot, 2007), a fact that contributes to ranking iron deficiency as the sixth risk factor for death and disability (WHO, 2015).

Although rice is a widely consumed food, it is not a rich source of iron, furthermore most of the Fe content of rice grains is accumulated in the aleurone and in the embryo, two parts that are lost during milling. After that, grains consist almost in its entirety of the endosperm, having lost up to $80 \%$ of the iron content and constituting a poor source of $\mathrm{Fe}$ for the human diet. This makes the evaluation of iron content in polished and unpolished grains an 
important piece of information when studying biofortification (Brinch-Pedersen et al., 2007; Paul et al., 2012; Bashir et al., 2013b).

Among plant breeding methods, transgenesis has high potential for Fe biofortification since this is a fast and efficient technique that is already being used for this purpose. Studies on rice biofortification by Fe using transgenesis were conducted using five different strategies. In the first strategy, the increase in the amount of $\mathrm{Fe}$ in the grain was achieved through the expression of soybean ferritin (SoyFerh1) under control of the Glutelin gene promoter from rice $(O s G L U B 1)$, which is specific for the endosperm. The higher expression of ferritin in the endosperm resulted in an at least two-fold increase of Fe in japonica cv. Kitaake (Goto et al., 1999) and in japonica cv. Taipei 309 (Lucca et al., 2001). The increase was 3.7-fold in indica cv. IR68144 (Vasconcelos et al., 2003) and 2.1-fold in indica cv. Pusa Sugandhi II (Paul et al., 2012).

In the second strategy, the increase in the amount of $\mathrm{Fe}$ in grains was due to the overexpression of genes involved in the synthesis of mugineic acid. When overexpressing Nicotianamine synthase $(N A S)$ it was possible to notice an Fe content increase of even more than threefold in polished grains of the japonica cultivars Tsukinohikari (Masuda et al., 2009), Dongjin (Lee et al., 2009b), and Nipponbare (Johnson et al., 2011). When Dioxigenase (IDS3) was overexpressed it caused an Fe content increase of 1.4-fold in polished grains of the japonica rice Tsukinohikari (Masuda et al., 2008).

In the third strategy, the OsYSL2 gene was inserted under the control of the promoter of Sucrose transporter $(O S S U T 1)$, resulting in increased expression of this gene in panicle and grains. This transformation increased by 4.4fold the concentration of Fe in polished grains of the japonica cultivar Tsukinohikari (Ishimaru et al., 2010). The fourth strategy is a combination of the first three, generating the rice "FER-NAS-YSL2", which presented a 4 to 6-fold increase in Fe content in polished grains of japonica cv. Tsukinohikari (Masuda et al., 2012), and a 3.4-fold increase in the other japonica cv. Paw Yin San (Aung et al., 2013).

Here it is interesting to note that Johnson et al. (2011) generated three populations of rice constitutively overexpressing OsNAS1, OsNAS2 or OsNAS3. In this study nicotianamine, $\mathrm{Fe}$ and $\mathrm{Zn}$ concentrations were significantly increased in unpolished grains of all of these three overexpression populations, with the highest concentrations in the $O s N A S 2$ and $O s N A S 3$ overexpression populations.

Trijatmiko et al. (2016) evaluated polished grains of transgenic events grown in field conditions in two countries and showed that event NASFer-274 (containing OsNAS2 and soybean ferritin ( $\mathrm{SferH}-\mathrm{l}$ ) genes) showed good results without yield penalty or altered grain quality.

In the fifth strategy, besides increasing the Fe content in the grain, it was sought to increase tolerance to Fe deficiency as well. In this case, a concurrent insertion was used, with the SoyFERH2 gene under the control of promoters of $O s G L U B 1$ and $O s G L B$, and also the $H v N A S 1$ genes Nicotianamine aminotransferase ( $H v N A A T-A$ and $H v N A A T-B)$ and Mugineic acid synthase (IDS3) of barley, which encode enzymes for the biosynthesis of MAs. Here the transformed plants were tolerant to Fe deficiency and also capable of accumulating 2.5 to 4 -fold of this mineral in polished grains (Masuda et al., 2013).

Also, the overexpression of the gene OSIRT1 using a constitutive promoter (maize ubiquitin), resulted in higher concentration of iron and zinc in shoots and roots and an increase in tolerance to iron deficiency at the seedling stage. It was also possible to detect an increase in the concentration of these metals in mature grains, with $13 \%$ more iron and $12 \%$ more zinc (Lee and An, 2009).

Similar data were found in plants overexpressing OsIRO2. These plants were shown to be more tolerant to iron deficiency and presented an increase in Fe content in shoots (two-fold increase) and grains (more than twice) when grown in calcareous soil (Ogo et al., 2011).

In addition, another strategy used is the knockdown of the gene OsVIT2, an important gene in the increase of iron concentration (Zhang et al., 2012). Bashir et al. (2013b) showed that transgenic OsVIT2-knockdown plants had an increase (1.8-fold) in the concentration of iron in polished grains. This suggests that the disruption of this gene helps in increasing the amount of iron in the grains, constituting a possible strategy for producing biofortified rice.

Although the strategies using transgenesis resulted in an increase in Fe content in grains, it is known that the polishing process is still responsible for major losses of this mineral. However, we should not forget that, the location of $\mathrm{Fe}$ in the grain may vary according to genotype (Doesthale et al., 1979; Sperotto et al., 2010). Thus, further studies should be conducted aiming to develop new strategies for internalization of Fe (Sperotto, 2013).

The flag leaves are the main source of photoassimilates for the development of seeds in rice. The Fe concentration of the flag leaf decreases during the reproductive development in rice, whereas the iron content of the grains increases. An interesting fact is that cultivars with lower Fe accumulation in grains show higher Fe accumulation in flag leaves. This was demonstrated in a study that showed that there is an iron remobilization from the flag leaves to the grains, and increasing this remobilization can help in obtaining biofortified grains (Sperotto et al., 2010). Still it is interesting to remember that other studies conducted by the same group showed that flag leaf removal (at anthesis) under field conditions did not affect seed Fe and $\mathrm{Zn}$ accumulation, suggesting that the flag leaves can be important, but not necessary, unless under low iron supply from the soil (Sperotto et al., 2013; Sperotto, 2013).

The commercialization of genetically modified Fe biofortified crops has some limitations, either by farmers (changes in the appearance of the product) and consumers 
(high cost and acceptance of genetically modified organisms). In this sense, methods based on the selection of genotypes that are rich in $\mathrm{Fe}$, followed by hybridization, may be better accepted (Zielinska-Dawidziak, 2015).

Rice Germplasm banks can be screened to identify genotypes that can absorb and store Fe more efficiently, so more QTLs related to these characteristics can be mapped and introgressed in elite varieties. In this case, one needs to take into account the natural variation that occurred during evolution, taking advantage of the effects of specific interactions between different genes and alleles (Schuler and Bauer, 2012; Pinson et al., 2015). An example of the potential for exploitation of these banks is the 4-fold difference found when comparing the iron content of aromatic and traditional varieties (Mulualem, 2015).

The natural variation related to $\mathrm{Fe}$ accumulation in rice grains that was already detected is quite low. In addition, grinding and polishing the grains results in a loss of up to $80 \%$ of this element (Brinch-Pedersen et al., 2007). Furthermore, the Fe concentration is deeply influenced by the interaction between genotype and environment (Graham et al., 1999). However, despite these limitations, the International Rice Research Institute (IRRI) has developed the cultivar IR68144, which has about twice the concentration of Fe when compared with local varieties used in the Philippines (Gregorio et al., 2000).

The development of cultivars with increased iron content in the grains, even at relatively low levels, associated with results of the characterization of 1,138 genotypes, that identified a variation of 6.3 to $24.4 \mu \mathrm{g} . \mathrm{g}^{-1}$ of $\mathrm{Fe}$ in grains, suggests that there is genetic potential for the development of other, new varieties with high accumulation of Fe (Gregorio et al., 2000; Mulualem, 2015). Furthermore, the genetic variability for the content of phytic acid can also be exploited, and these possibilities make the future of genetic progress seem really optimistic (Liu, 2005).

\section{Conclusions}

Being essential in the composition of different proteins and metabolic pathways, iron is vital for animal and plant health. Actually, it is an element capable of generating toxic effects due to its high bioavailability and is also a problem due to its low availability. To solve this problem, studies aiming the identification and understanding of pathways related to the regulation of iron metabolism are being conducted, combined with molecular markers in the identification of QTLs associated with these pathways. Furthermore, phylogeny can be used to better understand the evolution of the involved genes aiming not only to decrease the sensitivity of rice both to the lack and to the excess of iron in the soil, but also to help in the generation of biofortified plants with higher iron content in the grains.

Looking at these studies it is possible to see success, not only in the description of regulatory pathways, but also in breeding for improved varieties. Advances continue to be made and obstacles being overcome. In the future we should add efforts towards identifying more QTLs related to iron excess tolerance, and to increase iron content in grains. This, allied to the exploration of the existing variation for genes that have proven to be important in experiments involving transgenic analysis, should enable us to achieve greater market acceptance and to reduce bureaucratic obstacles, which greatly hinder the release of genetically modified organisms.

Although the genetic progress may seem difficult at certain times, our ability to deal with iron metabolism in rice has increased, and soon we should obtain cultivars that will be highly tolerant to iron stress, both against excess and lack of this mineral, and, allied to this, we should also be able to develop biofortified plants with higher content of iron in their grains, helping in the fight against anemia and providing better quality of life to humanity.

\section{Acknowledgments}

This work was supported by the Brazilian Ministry of Science and Technology, National Counsel of Technological and Scientific Development (CNPq); Coordination for the Improvement of Higher Education Personnel (CAPES) and the Rio Grande do Sul State Foundation for Research Support (FAPERGS).

\section{References}

Anuradha K, Agarwal S, Rao YV, Rao KV, Viraktamath BC and Sarla N (2012) Mapping QTLs and candidate genes for iron and zinc concentrations in unpolished rice of Madhukar Swarna RILs. Gene 508:233-240.

Arcanjo FPN, Santos PR and Arcanjo CPC (2013) Daily and weekly iron supplementations are effective in increasing hemoglobin and reducing anemia in infants. J Trop Pediatr 59:175-179.

Aung MS, Masuda H, Kobayashi T, Nakanishi H, Yamakawa T and Nishizawa NK (2013) Iron biofortification of myanmar rice. Front Plant Sci 4:158.

Bashir K, Inoue H, Nagasaka S, Takahashi M, Nakanishi H, Mori $S$ and Nishizawa NK (2006) Cloning and characterization of deoxymugineic acid synthase genes from graminaceous plants. J Biol Chem 281:32395-32402.

Bashir K, Ishimaru Y and Nishizawa NK (2010) Iron uptake and loading into rice grains. Rice 3:122-130.

Bashir K, Ishimaru Y, Shimo H, Nagasaka S, Fujimoto M, Takanashi H, Tsutsumi N, An G, Nakanishi H and Nishizawa NK (2011) The rice mitochondrial iron transporter is essential for plant growth. Nat Commun 2:322.

Bashir K, Nozoye T, Ishimaru Y, Nakanishi H and Nishizawa NK (2013a) Exploiting new tools for iron bio-fortification of rice. Biotechnol Adv 31:1624-1633.

Bashir K, Takahashi R, Akhtar S, Ishimaru Y, Nakanishi H and Nishizawa N (2013b) The knockdown of OsVIT2 and MIT affects iron localization in rice seed. Rice 6:31-37.

Becker M and Asch F (2005) Iron toxicity in rice - Conditions and management concepts. J Plant Nutr Soil Sci 168:558-573.

Belouchi A, Kwan T and Gros P (1997) Cloning and characterization of the OsNramp family from Oryza sativa, a new family 
of membrane proteins possibly implicated in the transport of metal ions. Plant Mol Biol 33:1085-92.

Bernal M, Casero D, Singh V, Wilson GT, Grande A, Yang H, Dodani SC, Pellegrini M, Huijser P, Connolly EL, et al. (2012) Transcriptome sequencing identifies SPL7-regulated copper acquisition genes FRO4/FRO5 and the copper dependence of iron homeostasis in Arabidopsis. Plant Cell 24:738-761.

Briat JF and Lobreaux S (1997) Iron transport and storage in plants. Trends Plant Sci 2:187-193.

Brinch-Pedersen H, Borg S, Tauris B and Holm PB (2007) Molecular genetic approaches to increasing mineral availability and vitamin content of cereals. J Cereal Sci 46:308-326.

Bughio N, Yamaguchi H, Nishizawa NK, Nakanishi H and Mori S (2002) Cloning an iron-regulated metal transporter from rice. J Exp Bot 53:1677-1682.

Cailliatte R, Schikora A, Briat JF, Mari S and Curie C (2010) High-affinity manganese uptake by the metal transporter NRAMP1 is essential for Arabidopsis growth in low manganese conditions. Plant Cell 22:904-917.

Chen WW, Yang JL, Qin C, Jin CW, Mo JH, Ye T and Zheng SJ (2010) Nitric oxide acts downstream of auxin to trigger root Ferric-Chelate Reductase activity in response to iron deficiency in Arabidopsis. Plant Physiol 154:810-819.

Colangelo EP and Guerinot ML (2004) The essential basic helix-loop-helix protein FIT1 is required for the iron deficiency response. Plant Cell Online 16:3400-3412.

Connolly EL and Guerinot M (2002) Iron stress in plants. Genome Biol 3:1024.1-1024.4.

Curie C, Alonso JM, Le Jean M, Ecker JR and Briat JF (2000) Involvement of NRAMP1 from Arabidopsis thaliana in iron transport. Biochem J 347:749-755.

Curie C, Panaviene Z, Loulergue C, Dellaporta SL, Briat JF and Walker EL (2001) Maize yellow stripe1 encodes a membrane protein directly involved in $\mathrm{Fe}(\mathrm{III})$ uptake. Nature 409:346-349.

Curie C and Briat J-F (2003) Iron transport and signaling in plants. Annu Rev Plant Biol 54:183-206.

Doesthale Y, Devara S, Rao S and Belavady B (1979) Effect of milling on mineral and trace element composition of raw and parboiled rice, J Sci Food Agric 30:40-46.

Du J, Zeng D, Wang B, Qian Q, Zheng S and Ling HQ (2013) Environmental effects on mineral accumulation in rice grains and identification of ecological specific QTLs. Environ Geochem Health 35:161-170.

Dufey I, Hakizimana P, Draye X, Lutts S and Bertin P (2009) QTL mapping for biomass and physiological parameters linked to resistance mechanisms to ferrous iron toxicity in rice. Euphytica 167:143-160.

Durrett TP, Gassmann W and Rogers EE (2007) The FRD3mediated efflux of citrate into the root vasculature is necessary for efficient iron translocation. Plant Physiol 144:197205.

Duy D, Stube R, Wanner G and Philippar K (2011) The chloroplast permease PIC1 regulates plant growth and development by directing homeostasis and transport of iron. Plant Physiol 155:1709-1722.

Eide D, Broderius M, Fett J and Guerinot ML (1996) A novel iron-regulated metal transporter from plants identified by functional expression in yeast. Proc Natl Acad Sci USA 93:5624-5628.
Feng H, An F, Zhang S, Ji Z, Ling H and Zuo J (2006) Lightregulated, tissue-specific, and cell differentiation-specific expression of the Arabidopsis Fe(III)-Chelate Reductase gene AtFRO6. 140:1345-1354.

Finatto T, de Oliveira AC, Chaparro C, da Maia LC, Farias DR, Woyann LG, Mistura CC, Soares-Bresolin AP, Llauro C, Panaud O, et al. (2015) Abiotic stress and genome dynamics: Specific genes and transposable elements response to iron excess in rice. Rice 8:13.

Fukuda A, Shiratsuchi H, Fukushima A, Yamaguchi H, Mochida H, Terao T and Ogiwara H (2012) Detection of chromosomal regions affecting iron concentration in rice shoots subjected to excess ferrous iron using chromosomal segment substitution lines between Japonica and Indica. Plant Prod Sci 15:183-191.

Furrer JL, Sanders DN, Hook-Barnard IG and McIntosh MA (2002) Export of the siderophore enterobactin in Escherichia coli: Involvement of a $43 \mathrm{kDa}$ membrane exporter. Mol Microbiol 44:1225-1234.

Giehl RFH, Lima JE and von Wirén N (2012) Localized iron supply triggers lateral root elongation in Arabidopsis by altering the AUX1-mediated auxin distribution Plant Cell 24:33-49.

Goff SA, Ricke D, Lan TH, Presting G, Wang R, Dunn M, Glazebrook J, Sessions A, Oeller P, Varma H, et al. (2002) A draft sequence of the rice genome (Oryza sativa L. ssp. japonica). Science 296:92-100.

Gollhofer J, Timofeev R, Lan P, Schmidt W and Buckhout TJ (2014) Vacuolar-iron-transporter1-like proteins mediate iron homeostasis in Arabidopsis. PLoS One 9:e110468.

Goto F, Yoshihara T, Shigemoto N, Toki S and Takaiwa F (1999) Iron fortification of rice seed by the soybean ferritin gene. Nat Biotechnol 17:282-286.

Graham R, Senadhira D, Beebe S, Iglesias C and Monasterio I (1999) Breeding for micronutrient density in edible portions of staple food crops: Conventional approaches. F Crop Res 60:57-80.

Gregorio G, Senadhira D, Htut H and Graham RR (2000) Breeding for trace mineral density in rice. Food Nutr Bull 21:382-386

Gross J, Stein RJ, Fett-Neto AG and Fett JP (2003) Iron homeostasis related genes in rice. Genet Mol Biol 26:477-497.

Gruber BD, Giehl RFH, Friedel S and von Wirén N (2013) Plasticity of the Arabidopsis root system under nutrient deficiencies. Plant Physiol 163:161-179.

Hell R and Stephan UW (2003) Iron uptake, trafficking and homeostasis in plants. Planta 216:541-551.

Hindt MN and Guerinot ML (2012) Getting a sense for signals: Regulation of the plant iron deficiency response. Biochim Biophys Acta 1823:1521-1530.

Hori T, Aoyagi T, Itoh H, Narihiro T, Oikawa A, Suzuki K, Ogata A, Friedrich MW, Conrad R and Kamagata Y (2015) Isolation of microorganisms involved in reduction of crystalline iron(III) oxides in natural environments. Front Microbiol $6: 386$.

Inoue H, Kobayashi T, Nozoye T, Takahashi M, Kakei Y, Suzuki K, Nakazono M, Nakanishi H, Mori S and Nishizawa NK (2009) Rice OsYSL15 is an iron-regulated Iron(III)-Deoxymugineic Acid Transporter expressed in the roots and is essential for iron uptake in early growth of the seedlings. J Biol Chem 284:3470-3479. 
Institute of Medicine (2001) Dietary reference intakes for Vitamin A, Vitamin K, Arsenic, Boron, Chromium, Copper, Iodine, Iron, Manganese, Molybdenum, Nickel, Silicon, Vanadium and Zinc. National Academy Press, Washington, DC, 773 p.

IRGSP - International Rice Genome Sequencing Project (2005) The map-based sequence of the rice genome. Nature 436:793-800.

Ishimaru Y, Suzuki M, Kobayashi T, Takahashi M, Nakanishi H, Mori S and Nishizawa NK (2005) OsZIP4, a novel zincregulated zinc transporter in rice. J Exp Bot 56:3207-3214.

Ishimaru Y, Suzuki M, Tsukamoto T, Suzuki K, Nakazono M, Kobayashi T, Wada Y, Watanabe S, Matsuhashi S, Takahashi $\mathrm{M}$, et al. (2006) Rice plants take up iron as an $\mathrm{Fe}^{3+}$ -phytosiderophore and as $\mathrm{Fe}^{2+}$. Plant J 45:335-346.

Ishimaru Y, Masuda H, Bashir K, Inoue H, Tsukamoto T, Takahashi M, Nakanishi H, Aoki N, Hirose T, Ohsugi R, et al. (2010) Rice metal-nicotianamine transporter, OSYSL2, is required for the long-distance transport of iron and manganese. Plant J 62:379-390.

Ishimaru Y, Bashir K, Nakanishi H and Nishizawa NK (2011) The role of rice phenolics efflux transporter in solubilizing apoplasmic iron. Plant Signal Behav 6:1624-1626.

Ishimaru Y, Takahashi R, Bashir K, Shimo H, Senoura T, Sugimoto K, Ono K, Yano M, Ishikawa S, Arao T, et al. (2012) Characterizing the role of rice NRAMP5 in manganese, iron and cadmium transport. Sci Rep 2:286.

Itai RN, Ogo Y, Kobayashi T, Nakanishi H and Nishizawa NK (2013) Rice genes involved in phytosiderophore biosynthesis are synchronously regulated during the early stages of iron deficiency in roots. Rice 6:16.

Jain A, Wilson GT and Connolly EL (2014) The diverse roles of FRO family metalloreductases in iron and copper homeostasis. Front Plant Sci 5:100.

Johnson AAT, Kyriacou B, Callahan DL, Carruthers L, Stangoulis J, Lombi E and Tester M (2011) Constitutive overexpression of the OsNAS gene family reveals single-gene strategies for effective iron- and zinc-biofortification of rice endosperm. PLoS One 6:e24476.

Jeong J, Cohu C, Kerkeb L, Pilon M, Connolly E and Guerinot ML (2008) Chloroplast Fe(III) chelate reductase activity is essential for seedling viability under iron limiting conditions. Proc Natl Acad Sci U S A 105:10619-10624.

Kim SA and Guerinot ML (2007) Mining iron: Iron uptake and transport in plants. FEBS Lett 581:2273-2280.

Kim SA, Punshon T, Lanzirotti A, Li L, Alonso JM, Ecker JR, Kaplan J and Guerinot ML (2006) Localization of iron in Arabidopsis seed requires the vacuolar membrane transporter VIT1. Science 314:1295-8.

Kobayashi T, Suzuki M, Inoue H, Itai RN, Takahashi M, Nakanishi H, Mori S and Nishizawa NK (2005) Expression of iron-acquisition-related genes in iron-deficient rice is coordinately induced by partially conserved iron-deficiencyresponsive elements. J Exp Bot 56:1305-1316.

Kobayashi T, Ogo Y, Itai RN, Nakanishi H, Takahashi M, Mori S and Nishizawa NK (2007) The transcription factor IDEF1 regulates the response to and tolerance of iron deficiency in plants. Proc Natl Acad Sci U S A 104:19150-19155.

Kobayashi T, Itai RN, Ogo Y, Kakei Y, Nakanishi H, Takahashi $M$ and Nishizawa NK (2009) The rice transcription factor IDEF1 is essential for the early response to iron deficiency, and induces vegetative expression of late embryogenesis abundant genes. Plant J 60:948-961.

Kobayashi T and Nishizawa NK (2012) Iron uptake, translocation, and regulation in higher plants. Annu Rev Plant Biol 63:131-152.

Kobayashi T, Nagasaka S, Senoura T, Itai RN, Nakanishi H and Nishizawa NK (2013) Iron-binding haemerythrin RING ubiquitin ligases regulate plant iron responses and accumulation. Nat Commun 4:1-12.

Kobayashi T and Nishizawa NK (2014) Iron sensors and signals in response to iron deficiency. Plant Sci 224:36-43.

Koike S, Inoue H, Mizuno D, Takahashi M, Nakanishi H, Mori S and Nishizawa NK (2004) OsYSL2 is a rice metal-nicotianamine transporter that is regulated by iron and expressed in the phloem. Plant J 39:415-424.

Kruger C, Berkowitz O, Stephan UW and Hell R (2002) A metal-binding member of the late embryogenesis abundant protein family transports iron in the phloem of Ricinus communis L. J Biol Chem 277:25062-25069.

Lee S and An G (2009) Over-expression of OsIRT1 leads to increased iron and zinc accumulations in rice. Plant Cell Environ 32:408-416.

Lee S, Chiecko JC, Kim SA, Walker EL, Lee Y, Guerinot ML and An G (2009a) Disruption of OSYSL15 leads to iron inefficiency in rice plants. Plant Physiol 150:786-800.

Lee S, Jeon US, Lee SJ, Kim YK, Persson DP, Husted S, Schjørring JK, Kakei Y, Masuda H, Nishizawa NK, et al. (2009b) Iron fortification of rice seeds through activation of the nicotianamine synthase gene. Proc Natl Acad Sci U S A 106:22014-22019.

Li L, Cheng X and Ling H (2004) Isolation and characterization of $\mathrm{Fe}$ (III)-chelate reductase gene LeFRO1 in tomato. Plant Mol Biol 54:125-136.

Li S, Pan XX, Berry JO, Wang Y, Naren, Ma S, Tan S, Xiao W, Zhao WZ, Sheng XY, et al. (2015) OsSEC24, a functional SEC24-like protein in rice, improves tolerance to iron deficiency and high $\mathrm{pH}$ by enhancing $\mathrm{H}^{+}$secretion mediated by PM-H ${ }^{+}$-ATPase. Plant Sci 233:61-71.

Li XL, Zhang HM, Ai Q, Liang G and Yu D (2016) Two bHLH transcription factors, bHLH34 and bHLH104, regulate iron homeostasis in Arabidopsis thaliana. Plant Physiol 170:2478-2493

Lingam S, Mohrbacher J, Brumbarova T, Potuschak T, FinkStraube C, Blondet E, Genschik P and Bauer P (2011) Interaction between the bHLH transcription factor FIT and Ethylene Insensitive3/Ethylene Insensitive3-Like1 reveals molecular linkage between the regulation of iron acquisition and ethylene signaling in Arabidopsis. Plant Cell 23:18151829.

Liu Z (2005) Grain phytic acid content in japonica rice as affected by cultivar and environment and its relation to protein content. Food Chem 89:49-52.

Long TA, Tsukagoshi H, Busch W, Lahner B, Salt DE and Benfey PN (2010) The bHLH transcription factor POPEYE regulates response to iron deficiency in Arabidopsis roots. Plant Cell Online 22:2219-2236.

Lucca P, Hurrell R and Potrykus I (2001) Genetic engineering approaches to improve the bioavailability and the level of iron in rice grains. Theor Appl Genet 102:392-397.

Lucena C, Waters BM, Romera FJ, García MJ, Morales M, Alcántara E and Pérez-Vicente R (2006) Ethylene could influence 
ferric reductase, iron transporter, and $\mathrm{H}^{+}$-ATPase gene expression by affecting FER (or FER-like) gene activity. J Exp Bot 57:4145-4154.

Majerus V, Bertin P, Swenden V, Fortemps A, Lobréaux S and Lutts S (2007) Organ-dependent responses of the african rice to short-term iron toxicity: Ferritin regulation and antioxidative responses. Biol Plant 51:303-312.

Marty F (1999) Plant vacuoles. Plant Cell 11:587-599.

Masuda H, Suzuki M, Morikawa KC, Kobayashi T, Nakanishi H, Takahashi M, Saigusa M, Mori S and Nishizawa NK (2008) Increase in Iron and zinc concentrations in rice grains via the introduction of barley genes involved in phytosiderophore synthesis. Rice 1:100-108.

Masuda H, Usuda K, Kobayashi T, Ishimaru Y, Kakei Y, Takahashi M, Higuchi K, Nakanishi H, Mori S and Nishizawa NK (2009) Overexpression of the barley nicotianamine synthase gene HvNAS1 increases iron and zinc concentrations in rice grains. Rice 2:155-166.

Masuda H, Ishimaru Y, Aung MS, Kobayashi T, Kakei Y, Takahashi M, Higuchi K, Nakanishi H and Nishizawa NK (2012) Iron biofortification in rice by the introduction of multiple genes involved in iron nutrition. Sci Rep 2:1-7.

Masuda H, Kobayashi T, Ishimaru Y, Takahashi M, Aung MS, Nakanishi H, Mori S and Nishizawa NK (2013) Iron-biofortification in rice by the introduction of three barley genes participated in mugineic acid biosynthesis with soybean ferritin gene. Front Plant Sci 4:132.

Merlot S, Hannibal L, Martins S, Martinelli L, Amir H, Lebrun M and Thomine S (2014) The metal transporter PgIREG1 from the hyperaccumulator Psychotria gabriellae is a candidate gene for nickel tolerance and accumulation. J Exp Bot 65:1551-1564.

Michelet B and Boutry M (1995) The plasma membrane H+-ATPase - A highly regulated enzyme with multiple physiological functions. Plant Physiol 108:1-6.

Milner MJ, Seamon J, Craft E and Kochian LV (2013) Transport properties of members of the ZIP family in plants and their role in $\mathrm{Zn}$ and Mn homeostasis. J Exp Bot 64:369-381.

Miroslav M (1998) The role of the redox system in uptake and translocation of iron by higher plants. Iugoslav Physiol Pharmacol Acta 34:479-489.

Mongon J, Konnerup D, Colmer TD and Rerkasem B (2014) Responses of rice to $\mathrm{Fe}^{2+}$ in aerated and stagnant conditions: Growth, root porosity and radial oxygen loss barrier. Funct Plant Biol 41:922-929.

Moretti D, Zimmermann MB, Muthayya S, Thankachan P, Lee TC, Kurpad AV and Hurrell RF (2006) Extruded rice fortified with micronized ground ferric pyrophosphate reduces iron deficiency in Indian schoolchildren: A double-blind randomized controlled trial1-3. Am J Clin Nutr 84:822-829.

Morrissey J and Guerinot ML (2009) Iron uptake and transport in plants: The good, the bad, and the ionome. Chem Rev 109:4553-4567.

Morrissey J, Baxter IR, Lee J, Li L, Lahner B, Grotz N, Kaplan J, Salt DE and Guerinot ML (2009) The ferroportin metal efflux proteins function in iron and cobalt homeostasis in Arabidopsis. Plant Cell 21:3326-3338.

Mulualem T (2015) Application of bio-fortification through plant breeding to improve the value of staple crops. Biomedicine and Biotechnology 3:11-19.
Nakanishi H, Yamaguchi H, Sasakuma T, Nishizawa NK and Mori S (2000) Two dioxygenase genes, Ids3 and Ids2, from Hordeum vulgare are involved in the biosynthesis of mugineic acid family phytosiderophores. Plant Mol Biol 44:199-207.

Narayanan NN, Vasconcelos MW and Grusak MA (2007) Expression profiling of Oryza sativa metal homeostasis genes in different rice cultivars using a cDNA macroarray. Plant Physiol Biochem 45:277-286.

Nawaz Z, Kakar KU, Li X, Li S, Zhang B, Shou H and Shu Q (2015) Genome-wide association mapping of Quantitative Trait Loci (QTLs) for contents of eight elements in Brown Rice (Oryza sativa L.). J Agric Food Chem 63:8008-8016.

Nevo Y and Nelson N (2006) The NRAMP family of metal-ion transporters. Biochim Biophys Acta - Mol Cell Res 1763:609-620.

Norton GJ, Deacon CM, Xiong L, Huang S, Meharg AA and Price AH (2010) Genetic mapping of the rice ionome in leaves and grain: Identification of QTLs for 17 elements including arsenic, cadmium, iron and selenium. Plant Soil 329:139-153.

Nozoye T, Nagasaka S, Kobayashi T, Takahashi M, Sato Y, Sato Y, Uozumi N, Nakanishi H and Nishizawa NK (2011) Phytosiderophore efflux transporters are crucial for iron acquisition in graminaceous plants. J Biol Chem 286:5446-5454.

Ogo Y, Nakanishi Itai R, Nakanishi H, Kobayashi T, Takahashi M, Mori S and Nishizawa NK (2007) The rice bHLH protein $\mathrm{OSIRO} 2$ is an essential regulator of the genes involved in $\mathrm{Fe}$ uptake under Fe-deficient conditions. Plant J 51:366-377.

Ogo Y, Kobayashi T, Nakanishi Itai R, Nakanishi H, Kakei Y, Takahashi M, Toki S, Mori S and Nishizawa NK (2008) A novel NAC transcription factor, IDEF2, that recognizes the iron deficiency-responsive element 2 regulates the genes involved in iron homeostasis in plants. J Biol Chem 283:13407-13417.

Ogo Y, Itai RN, Kobayashi T, Aung MS, Nakanishi H and Nishizawa NK (2011) OsIRO2 is responsible for iron utilization in rice and improves growth and yield in calcareous soil. Plant Mol Biol 75:593-605.

Palmer CM and Guerinot ML (2009) Facing the challenges of $\mathrm{Cu}$, Fe and Zn homeostasis in plants. Nat Chem Biol 5:333-340.

Panda BB, Sharma S, Mohapatra PK and Das A (2014) Iron nutrition vis-à-vis aconitase activity and ferritin accumulation in tropical Indica Rice cultivars differing in grain iron concentration. Am J Plant Sci 5:2829-2841.

Pao SS, Paulsen IT and Saier Jr MH (1998) Major facilitator superfamily. Microbiol Mol Biol Rev 62:1-34.

Paul S, Ali N, Gayen D, Datta SK and Datta K (2012) Molecular breeding of Osfer 2 gene to increase iron nutrition in rice grain. GM Crops Food 3:310-6.

Peng J-S and Gong J-M (2014) Vacuolar sequestration capacity and long-distance metal transport in plants. Front Plant Sci 5:1-5.

Petit JM, Van Wuytswinkel O, Briat JF and Lobréaux S (2001) Characterization of an iron-dependent regulatory sequence involved in the transcriptional control of AtFer1 and ZmFer1 plant ferritin genes by iron. J Biol Chem 276:5584-5590.

Pinson SRM, Tarpley L, Yan W, Yeater K, Lahner B, Yakubova E, Huang X, Zhang M, Guerinot ML and Salt DE (2015) Worldwide genetic diversity for mineral element concentrations in rice grain. Crop Sci 55:294-311. 
Pittman JK (2005) Managing the manganese: Molecular mechanisms of manganese transport and homeostasis. New Phytol 167:733-742.

Placido F, Arcanjo N, Santos PR and Segall SD (2013) Ferric pyrophosphate-fortified rice given once weekly does not increase hemoglobin levels in preschoolers. J Rice Res 1:1-5.

Qu LQ, Yoshihara T, Ooyama A, Goto F and Takaiwa F (2005) Iron accumulation does not parallel the high expression level of ferritin in transgenic rice seeds. Planta 222:225-33.

Quinet M, Vromman D, Clippe A, Bertin P, Lequeux H, Dufey I, Lutts S and Lefèvre I (2012) Combined transcriptomic and physiological approaches reveal strong differences between short- and long-term response of rice (Oryza sativa) to iron toxicity. Plant Cell Environ 35:1837-1859.

Raboy V (2002) Progress in breeding low phytate crops. J Nutr 503-505.

Ricachenevsky FK and Sperotto RA (2014) There and back again, or always there? The evolution of rice combined strategy for Fe uptake. Front Plant Sci 5:189.

Rodríguez-Celma J and Schmidt W (2013) Reduction-based iron uptake revisited on the role of secreted iron-binding compounds. Plant Signal Behav 8:e26116.

Rodríguez-Celma J, Lin W-D, Fu G-M, Abadía J, López-Millán A-F and Schmidt W (2013) Mutually exclusive alterations in secondary metabolism are critical for the uptake of insoluble iron compounds by Arabidopsis and Medicago truncatula. Plant Physiol 162:1473-1485.

Rout GR and Sahoo S. (2015) Role of iron in plant growth and metabolism Rev Agric Sci 3:1-24.

Romheld V and Marschner H (1986) Evidence for a specific uptake system for iron phytosiderophores in roots of grasses. Plant Physiol 80:175-180.

Sahrawat KL (2004) Managing iron toxicity in lowland rice: The role of tolerant genotypes and plant nutrients. In: Rice is life: Scientific perspectives for the 21 st century. Proceedings of the World Rice Research Conference, Tsukuba, pp 452-455.

Santi S and Schmidt W (2009) Dissecting iron deficiency-induced proton extrusion in Arabidopsis roots. New Phytol 183:1072-1084.

Santos LS and de Oliveira AC (2007) Rice iron metabolism: From source to solution. J Crop Sci Biotechnol 10:64-72.

Sasaki A, Yamaji N, Yokosho K and Ma JF (2012) Nramp5 is a major transporter responsible for manganese and cadmium uptake in rice. Plant Cell 24:2155-2167.

Schuler M and Bauer P (2012) Strategies for iron biofortification of crop plants. In: Kapiris K (ed) Food Quality, InTech. Available

from: http://www.intechopen.com/books/food-quality/strategies-for-iron-biofortification-of-crop-plants.

Shahid M, Nayak AK, Shukla AK, Tripathi R, Kumar A, Raja R, Panda BB, Meher J, Bhattacharyya P and Dash D (2014) Mitigation of iron toxicity and Iron, Zinc, and Manganese nutrition of Wetland Rice Cultivars (Oryza sativa L.) grown in iron-toxic soil. CLEAN - Soil Air Water 42:1604-1609.

Shimizu A (2009) QTL analysis of genetic tolerance to iron toxicity in rice (Oryza sativa L.) by quantification of bronzing score. J New Seeds 10:171-179.

Shojima S, Nishizawa N-K, Fushiya S, Nozoe S, Irifune T and Mori S (1990) Biosynthesis of phytosiderophores. Plant Physiol 93:1497-1503.
Silveira VC da, Fadanelli C, Sperotto RA, Stein RJ, Basso LA, Santos DS, Vaz Junior IDS, Dias JF and Fett JP (2009) Role of ferritin in the rice tolerance to iron overload. Sci Agric 66:549-555

Sperotto RA (2013) Zn/Fe remobilization from vegetative tissues to rice seeds: Should I stay or should I go? Ask $\mathrm{Zn} / \mathrm{Fe}$ supply! Front Plant Sci 4:464.

Sperotto RA, Boff T, Duarte GL, Santos LS, Grusak MA and Fett JP (2010) Identification of putative target genes to manipulate $\mathrm{Fe}$ and $\mathrm{Zn}$ concentrations in rice grains. J Plant Physiol 167:1500-1506.

Sperotto RA, Vasconcelos MW, Grusak MA and Fett JP (2012) Effects of different Fe supplies on mineral partitioning and remobilization during the reproductive development of rice (Oryza sativa L.). Rice 5:27.

Sperotto RA, Ricachenevsky FK, Waldow VA, Müller ALH, Dressler VL and Fett JP (2013) Rice grain Fe, Mn and Zn accumulation: How important are flag leaves and seed number? Plant Soil Environ 59:262-266.

Stein RJ, Ricachenevsky FK and Fett JP (2009) Differential regulation of the two rice ferritin genes (OsFER1 and OsFER2). Plant Sci 177:563-569.

Suzuki M, Takahashi M, Tsukamoto T, Watanabe S, Matsuhashi S, Yazaki J, Kishimoto N, Kikuchi S, Nakanishi H, Mori S, et al. (2006) Biosynthesis and secretion of mugineic acid family phytosiderophores in zinc-deficient barley. Plant J 48:85-97.

Takahashi M, Terada Y, Nakai I, Nakanishi H, Yoshimura E, Mori S and Nishizawa NK (2003) Role of nicotianamine in the intracellular delivery of metals and plant reproductive development. Plant Cell 15:1263-1280.

Takahashi R, Ishimaru Y, Nakanishi $\mathrm{H}$ and Nishizawa NK (2011a) Role of the iron transporter OsNRAMP1 in cadmium uptake and accumulation in rice. Plant Signal Behav 6:1813-1816.

Takahashi R, Ishimaru Y, Senoura T, Shimo H, Ishikawa S, Arao T, Nakanishi $\mathrm{H}$ and Nishizawa NK (2011b) The OsNRAMP1 iron transporter is involved in Cd accumulation in rice. J Exp Bot 62:4843-4850.

Trijatmiko KR, Dueñas C, Tsakirpaloglou N, Torrizo L, Arines FM, Adeva C, Balindong J, Oliva N, Sapasap MV, Borrero $\mathrm{J}$, et al. (2016) Biofortified indica rice attains iron and zinc nutrition dietary targets in the field. Sci Rep 6:19792.

Vasconcelos M, Datta K, Oliva N, Khalekuzzaman M, Torrizo L, Krishnan S, Oliveira M, Goto F and Datta SK (2003) Enhanced iron and zinc accumulation in transgenic rice with the ferritin gene. Plant Sci 164:371-378.

Vert G, Grotz N, Dedaldechamp F, Gaymard F, Guerinot ML, Briat JF and Curie C (2002) IRT1, an Arabidopsis transporter essential for iron uptake from the soil and plant growth. Plant Cell 14:1223-1233.

Victoria FDC, Bervald CMP, da Maia LC, de Sousa RO, Panaud $\mathrm{O}$ and de Oliveira AC (2012) Phylogenetic relationships and selective pressure on gene families related to iron homeostasis in land plants. Genome 55:883-900.

Vigani G, Tarantino D and Murgia I (2013) Mitochondrial ferritin is a functional iron-storage protein in cucumber (Cucumis sativus) roots. Front Plant Sci 4:316.

Visser J and Herselman M (2013) Anaemia in South Africa: The past, the present and the future. S Afr J Clin Nutr 26:166167. 
Vreugdenhil D, Aarts MGM, Koornneef M, Nelissen H and Ernst WHO (2004) Natural variation and QTL analysis for cationic mineral content in seeds of Arabidopsis thaliana. Plant Cell Environ 27:828-839.

Waters BM, Blevins DG and Eide DJ (2002) Characterization of FRO1, a pea ferric-chelate reductase involved in root iron acquisition. Plant Physiol 129:85-94.

Wan JL, Zhai HQ and Ikehashi H (2003) Detection and analysis of QTLs for ferrous iron toxicity tolerance in rice, Oryza sativa L. Euphytica 131:201-206.

Wan JL, Zhai HQ, Wan JM, Yasuiu H and Yoshimura A (2003) Mapping QTL for traits associated with resistance to ferrous iron toxicity in rice (Oryza sativa L.), using japonica chromosome segment substitution lines. Yi Chuan Xue Bao 30:893-898.

White P and Broadley M (2005) Biofortifying crops with essential mineral elements. Trends Plant Sci 10:586-593.

Widodo B, Broadley MR, Rose T, Frei M, Pariasca-Tanaka J, Yoshihashi T, Thomson M, Hammond JP, Aprile A, Close TJ, et al. (2010) Response to zinc deficiency of two rice lines with contrasting tolerance is determined by root growth maintenance and organic acid exudation rates, and not by zinc-transporter activity. New Phytol 400-414.

Wu L, Shhadi MY, Gregorio G, Matthus E, Becker M and Frei M (2014) Genetic and physiological analysis of tolerance to acute iron toxicity in rice. Rice 7:8.

Wu P, Hu B, Liao CY, Zhu JM, Wu YR, Senadhira D and Paterson AH (1998) Characterization of tissue tolerance to iron by molecular markers in different lines of rice. Plant and Soil 203:217-226.

Yang M, Zhang W, Dong H, Zhang Y, Lv K, Wang D and Lian X (2013) OsNRAMP3 is a vascular bundles-specific manganese transporter that is responsible for manganese distribution in rice. PLoS One 8:e83990.

Yang X, Song J, Campbell-Palmer L, Fillmore S and Zhang Z (2013) Effect of ethylene and 1-MCP on expression of genes involved in ethylene biosynthesis and perception during ripening of apple fruit. Postharvest Biol Technol 78:55-66.

Yao W, Li G, Zhao H, Wang G, Lian X and Xie W (2015) Exploring the rice dispensable genome using a metagenomelike assembly strategy. Genome Biol 16:187.

Yokosho K, Yamaji N, Ueno D, Mitani N and Ma JF (2009) OsFRDL1 Is a citrate transporter required for efficient translocation of iron in rice. Plant Physiol 149:297-305.

Yuan Y, Wu H, Wang N, Li J, Zhao W, Du J, Wang D and Ling H-Q (2008) FIT interacts with AtbHLH38 and AtbHLH39 in regulating iron uptake gene expression for iron homeostasis in Arabidopsis. Cell Res 18:385-397.
Zaharieva T and Römheld V (2000) Specific $\mathrm{Fe}^{2+}$ uptake system in strategy I plants inducible under Fe deficiency, J Plant Nutr 18:1733-1744.

Zhang M, Pinson SRM, Tarpley L, Huang XY, Lahner B, Yakubova E, Baxter I, Guerinot ML and Salt DE (2014) Mapping and validation of quantitative trait loci associated with concentrations of 16 elements in unmilled rice grain. Theor Appl Genet 127:137-165.

Zhang Y, Xu YH, Yi HY and Gong JM (2012) Vacuolar membrane transporters OsVIT1 and OsVIT2 modulate iron translocation between flag leaves and seeds in rice. Plant $\mathrm{J}$ 72:400-410.

Zhao M, Song A, Li P, Chen S, Jiang J and Chen F (2014) A bHLH transcription factor regulates iron intake under Fe deficiency in chrysanthemum. Scientific Reports 4:6694.

Zheng L, Ying Y, Wang L, Wang F, Whelan J and Shou H (2010) Identification of a novel iron regulated basic helix-loophelix protein involved in Fe homeostasis in Oryza sativa. BMC Plant Biol 10:166.

Zhu Y, Di T, Xu G, Chen X, Zeng H, Yan F and Shen Q (2009) Adaptation of plasma membrane $\mathrm{H}^{+}$-ATPase of rice roots to low $\mathrm{pH}$ as related to ammonium nutrition. Plant, Cell Environ 32:1428-1440.

Zielinska-Dawidziak M (2015) Plant ferritin - A source of iron to prevent its deficiency. Nutrients 7:1184-1201.

\section{Internet Resources}

Companhia Nacional de Abastecimento (CONAB), http://www.conab.gov.br/ (August 10, 2015).

FAOSTAT (2015) Food and Agriculture Organization of The United Nations - Statistics Division (FAOSTAT), http://faostat3.fao.org/download/Q/QC/E (August 31, 2015).

WHO (2015) World Health Organization, http:/www.who.int/nutrition/publications/en/ida_assessment_prevention_control.pdf (December 05, 2015).

\section{Supplementary Material}

The following online material is available for this article: Table S1 - Positions of the QTLs related to Fe metabolism shown in Figure 3.

Associate Editor: Marcia Pinheiro Margis

License information: This is an open-access article distributed under the terms of the Creative Commons Attribution License (type CC-BY), which permits unrestricted use, distribution and reproduction in any medium, provided the original article is properly cited. 